\title{
Editorial
}

\section{Decision Support for the Provision of Ecosystem Services under Climate Change: An Editorial}

\section{Harald Vacik ${ }^{1, *}$, José G. Borges ${ }^{2}$, Jordi Garcia-Gonzalo ${ }^{2}$ and Ljusk-Ola Eriksson ${ }^{3}$}

1 Department of Forest and Soil Sciences, Institute of Silviculture, University of Natural Resources and Life Sciences, Vienna A-1190, Austria

2 Forest Research Centre, School of Agriculture, University of Lisbon, Lisbon 1349-017, Portugal; E-Mails: joseborges@ isa.ulisboa.pt (J.G.B.); jordigarcia@ isa.ulisboa.pt (J.G.-G.)

3 Department of Forest Resource Management, Swedish University of Agricultural Sciences Umea, Umea SE-901 83, Sweden; E-Mail: Ljusk.Ola.Eriksson@slu.se

* Author to whom correspondence should be addressed; E-Mail: harald.vacik@boku.ac.at; Tel.: +43-1-47654-4052; Fax: +43-1-47654-4092.

Academic Editor: Eric J. Jokela

Received: 8 September 2015 / Accepted: 11 September 2015 / Published: 16 September 2015

\begin{abstract}
The Special Issue "Providing Ecosystem Services under Climate Change: Community of Practice of Forest Decision Support Systems" is based on the presentations given at the 24th World Congress of the International Union of Forest Research Organizations and provides an overview on Forest Management Decision Support Systems currently designed and applied for the sustained provision of ecosystem services within the context of climate change. The contributions provide an overview on models, methods, techniques used in decision support and the proposed frameworks to support decision making. With populations and economies growing worldwide, the demands on forest resources increase, and sustaining the supply of ecosystem services becomes crucial. Through growing public participation in decisions regarding the management of natural resources, new demands have emerged for tools that support our understanding of environmental issues, and for the development and evaluation of alternative management options; there is a desire to project the consequences of different courses of action. Decision Support Systems (DSS) have been proven to solve such ill-structured decision problems by integrating database management systems with analytical and operational research models, thus providing various reporting capabilities. Several case studies focus on decision problems, the development and evaluation of alternative management options,
\end{abstract}


and on projecting the consequences of different courses of action in the provision of ecosystem services. Conclusions on the state-of-the-art in decision support and the needed advances in research are drawn.

Keywords: decision support systems; ecosystem services; climate change; models; methods

\section{Introduction}

Forests can provide a large number of ecosystem services to the public and contribute to the income of land owners worldwide. Through the variety of ecological site conditions and different economic constraints, forest management has to address complex planning tasks. In the last few decades, forestry has passed through a considerable change of its socio-cultural acceptance and public perception. Due to the often conflicting interests in land-use planning, decision makers recognized the need to involve stakeholders who are affected by the decisions they take, and who have the power to influence their outcome. The emerging issues rising from discussions about maintaining biodiversity, securing bioenergy demands, and addressing climate change with adaptive forest management, stimulated the development and application of computer-based tools. With populations and economies growing worldwide, the demands on forest resources increase, and sustaining the supply of ecosystem services becomes crucial. Through growing public participation in decisions regarding the management of natural resources, new demands have emerged for tools that support our understanding of environmental issues, and for the development and evaluation of alternative management options; there is a desire to project the consequences of different courses of action. Decision Support Systems (DSS) have been proven to solve such ill-structured decision problems by integrating database management systems with analytical and operational research models, thus providing various reporting capabilities. A number of DSS related conferences (Vienna 2003, Edinburgh 2005, Lisbon 2009, Umea 2013) has provided a sound theoretical basis for decision support and showed forest management applications in a wider context [1]. The latest compilation of forest management decision support systems is found in the report [2] and special issue [3] of the related European Cooperation in Science and Technology (COST) Action FORSYS. The emphasis was on identifying and assessing the support provided by computerized tools to enhance forest management planning in real-world contexts. The applications focused on planning problems that prevail world-wide and allowed to discuss the architecture and the components of the tools used to address them. During the World Congress of the International Union of Forest Research Organizations (IUFRO) in Salt Lake City in autumn 2014, a session explored how the field of Decision Support Systems (DSS) is currently expanding, ranging from examples in the US and Europe, focusing on different contexts. This Special Issue provides an overview on how DSS are designed and applied for the sustained provision of ecosystem services within the context of climate change. The issue includes an overview on models, methods, techniques, and frameworks used in natural resource management. Several case studies focus on ill-structured decision problems, on the development and evaluation of alternative management options, and on 
projecting the consequences of different courses of action, so as to support our understanding of environmental issues.

\section{Decision Support Systems}

DSS are computer-based systems that help decision makers to analyze and solve ill-structured decision problems by integrating database management systems with analytical and operational research models, graphic and tabular reporting capabilities, and the expert knowledge of scientists, managers, and decision makers. According to [4], a DSS includes three major components: A dialog subsystem, a data base subsystem, and a model base subsystem. The components of this model-driven definition can be related to the trilogy of interface subsystem, knowledge subsystem, and problem processing subsystem, as proposed by [5]. Each DSS project is following a certain philosophy and tries to best meet the demands of the decision makers in order to manage forests to provide ecosystem services under climate change.

In this Special Issue, four different spatial decision support approaches allow reviewing the state of art in considering spatial and temporal dimensions in forest management planning. Firstly Reynolds et al. [6] discuss, in their review, the design features behind the success of the Ecosystem Management Decision Support System (EMDS) and propose the needs for the next generation of spatial decision support for adaptive management under climate change. Generality, transparency, simplification, abstraction and complexity, as well as the consideration of the spatial scale have been identified as critical for the success of the EMDS system, and deserve careful consideration in the design of decision-support systems for natural resource management. Following this recommendations, Frank et al. [7] demonstrate the platform GISCAME to model spatio-temporal dynamics of biomass production at a regional scale in order to identify land use strategies that enhance biomass provision and avoid trade-offs for other ecosystem services. The results showed that forest conversion towards climate-change-adapted forest types had positive effects on ecological integrity and landscape aesthetics. Marušák et al. [8] introduce the GIS tool Optimal for supporting spatial and temporal decisions in harvest scheduling. The DSS is designed and applied for silvicultural systems comprising clear-cuts and shelterwood systems with respect to the environmental and economic constraints. Forest managers are enabled to create and check spatial limits of harvest units and create various scenarios with Optimal. Daleman et al. [9] introduce the concept, characteristics, functionalities, components and use of the Sim4Tree DSS, which supports strategic and tactical forestry planning by providing simulations of forest development, ecosystem services potential and economic performance through time, from a regional to a stand scale, under various management and climate regimes. Finally, Biber et al. [10] compiled scenario runs from regionally tailored forest growth models and DSS from 20 case studies throughout Europe and analyzed whether the ecosystem service provision depends on management intensity and other co-variables, comprising regional affiliation, social environment, and tree species composition. They found a strong positive correlation between management intensity and wood production, but only weak correlation with protective and socioeconomic forest functions. 


\section{Decision Support Methods}

In addition to the presentation of various DSS, several advances in decision support techniques were identified, ranging from multi-attribute to multi-objective decision making methods. Garcia-Gonzalo et al. [11] demonstrate the integration of an Interactive Decision Maps (IDM) technique within a DSS for an interactive visualization of the Pareto frontier. The multi-objective forest planning scenario of 1 million ha of cork and holm oak forest ecosystems in Southern Portugal is facilitated by stakeholder participation. Kašpar et al. [12] present an approach where multiple criteria programming and integer programming techniques are used to find an optimal program of forest harvesting with respect to both economic and environmental constraints. Aldea et al. [13] propose a goal programming procedure for integrating ecosystem services into forest management including a deterministic and a Monte Carlo modeling approach. Similar to other authors they highlight the variability of the results depending on the methodological approach taken and propose to critically evaluate the methodological approach taken. In this context also Estrella et al. [14] introduced three different ideal point-based multi-criteria decision methods, i.e., iterative ideal point thresholding (IIPT), compromise programming (CP) and balanced compromise programming (BCP) to find an optimal distribution of land use types for regional land performance. For most ecosystem service analyzed, CP and BCP produced balanced results that were closer to the absolute optimal values when compared to IIPT. From the wide field of multi-criteria decision making techniques, Mendoza et al. [15] compare different forest management schemes of Mexico in order to identify best management approaches considering multi-resources, environmental impacts and non-timber values. Considering the increased need for the involvement of preferences of decision makers, Rinaldi et al. [16] provide an example of how forest owner specific characterization can be integrated in a DSS by linking a behavioral harvesting decision model to a forest resource dynamics model. They showed that the distribution of different owner types on forestland affects harvesting intensity and inter-temporal forest development.

\section{Conclusions}

The presenters provided an overview about the different models, methods and techniques applied to support decision making under changing environmental conditions and the challenges they have to tackle in tailoring the DSS to the needs of the decision makers. DSS are becoming more important in increasing the transparency of decision making processes, supporting a formal evaluation of decision alternatives and allow including various stakeholders and actors in decision making.

There is a strong need for DSS to consider growth models and ecosystem models that are capable in addressing changing environmental conditions, including biotic and abiotic disturbance agents and allow an evaluation for multiple ecosystem services. DSS should provide frameworks that allow considering uncertainties in decision making, and provide possibilities for risk evaluation.

The contributions to this Special Issue highlight that the development in decision support for forest management is set by decision theory, available technology, and methods. In addition to the technological and methodological advances, there is a strong need to include decision makers and DSS users in the design of the DSS from the very beginning in order to better meet their demands. Demands for new advances in decision support are emerging from the rising challenges and problems in forest 
management acting as stimuli for the science community [17]. Decision analysts and scientists try to cover the complexity of the real world with sophisticated models and methods in their development of new and adaptation of existing DSS. The presented examples show that there is a need to combine different methodological approaches [10], include uncertainty analysis [13], and provide different means to communicate the results to the user [11]. Decision makers expect easy to use and smart tools, which are capable in addressing the challenges of adaptive forest management in a sustained provision of ecosystem services within the context of climate change. Thus, there is a dilemma upcoming in addressing all aspects of complex decision-making contexts in forest management while still trying to design simple applications according to user demands.

The exchange of experiences and lessons learned from the development and application of DSS is therefore becoming more and more important. The Community of Practice of Forest Management Decision Support Systems [18] has a well-established user community, with members from research, public bodies, business and NGOs. The readers are therefore invited to contribute to the continuation of the network activities in connecting and mobilizing developers and users of DSS to support the planning and sustainable use of forest resources in a changing world.

\section{Acknowledgments}

The authors would like to thank all authors contributing to this Special Issue and for providing insight on Forest Management Decision Support Systems currently designed and applied for the sustained provision of ecosystem services within the context of climate change. Special thank goes to the Journal Editors of Forests for providing substantial support in handling the manuscripts and reviews.

\section{Author Contributions}

Harald Vacik, José G. Borges, Jordi Garcia-Gonzalo and Ljusk-Ola Eriksson designed the contributions to the Special Issue and interpreted the results. Harald Vacik wrote the paper, all co-authors contributed to the writing.

\section{Conflicts of Interest}

The authors declare no conflict of interest.

\section{References}

1. Rauscher M.H.; Reynolds K.M.; Vacik H. Decision support systems for forest management. Comput. Electron. Agric. 2005, 49, 1-5.

2. Borges, J.G.; Nordström, E.-M.; Garcia Gonzalo, J.; Hujala, T.; Trasobares, A. Computer-based Tools for Supporting Forest Management. The Experience and the Expertise World-wide; Department of Forest Resource Management, Swedish University of Agricultural Sciences: Umeå, Sweden, 2014.

3. Borges J.G.; Eriksson, L.O. Foreword: Special Issue: Decision support systems for sustainable forest management. Scand. J. For. Res. 2014, 29, doi:10.1080/02827581.2014.951513. 
4. Watson H.J.; Sprague R.H. The components of an architecture for DSS. In Decision Support Systems: Putting Theory into Practice, 3rd ed.; Sprague, R.H., Watson, H.J., Eds.; Prentice-Hall: New York, NY, USA, 1993.

5. Holsapple C.W.; Whinston A.B. Decision Support Systems: A Knowledge-Based Approach; West Publishing: St. Paul, MN, USA, 1996.

6. Reynolds, K.; Paplanus, S.; Miller, B.; Murphy, P. Design features behind success of the ecosystem management decision support system and future development. Forests 2015, 6, 27-46.

7. Frank, S.; Fürst, C.; Pietzsch, F. Cross-sectoral resource management: How forest management alternatives affect the provision of biomass and other ecosystem services. Forests 2015, 6, 533-560.

8. Marušák, R.; Kašpar, J.; Vopěnka, P. Decision Support Systems (DSS) optimal—A case study from the Czech Republic. Forests 2015, 6, 163-182.

9. Dalemans, F.; Jacxsens, P.; van Orshoven, J.; Kint, V.; Moonen, P.; Muys, B. Assisting sustainable forest management and forest policy planning with the Sim4Tree decision support system. Forests 2015, 6, 859-878.

10. Biber, P.; Borges, J.G.; Moshammer, R.; Barreiro, S.; Botequim, B.; Brodrechtová, Y.; Brukas, V.; Chirici, G.; Cordero-Debets, R.; Corrigan, E.; et al. How sensitive are ecosystem services in european forest landscapes to silvicultural treatment? Forests 2015, 6, 1666-1695.

11. Garcia-Gonzalo, J.; Bushenkov, V.; McDill, M.E.; Borges, J.G. A decision support system for assessing trade-offs between ecosystem management goals: An application in Portugal. Forests 2015, 6, 65-87.

12. Kašpar, J.; Marušák, R.; Hlavatý, R. A forest planning approach with respect to the creation of overmature reserved areas in managed forests. Forests 2015, 6, 328-343.

13. Aldea, J.; Martínez-Peña, F.; Romero, C.; Diaz-Balteiro, L. Participatory goal programming in forest management: An application integrating several ecosystem services. Forests 2014, 5, 3352-3371.

14. Estrella, R.; Cattrysse, D.; van Orshoven, J. Comparison of three ideal point-based multi-criteria decision methods for afforestation planning. Forests 2014, 5, 3222-3240.

15. Mendoza, M.A.; Fajardo, J.J.; Curiel, G.; Domínguez, F.; Apodaca, M.; Rodríguez-Camarillo, M.G.; Zepeta, J. Harvest regulation for multi-resource management, old and new approaches (old and new). Forests 2015, 6, 670-691.

16. Rinaldi, F.; Jonsson, R.; Sallnäs, O.; Trubins, R. Behavioral modelling in a decision support system. Forests 2015, 6, 311-327.

17. Vacik, H.; Lexer, M.J. Past, current and future drivers for the development of decision support systems in forest management. Scand. J. For. Res. 2014, 29, 2-19.

18. Community of Practice of Forest Management Decision Support Systems. Available online: http://www.forestdss.org (accessed on 8 September 2015).

(C) 2015 by the authors; licensee MDPI, Basel, Switzerland. This article is an open access article distributed under the terms and conditions of the Creative Commons Attribution license (http://creativecommons.org/licenses/by/4.0/). 